\title{
Herpes simplex virus type 2-associated recurrent aseptic (Mollaret's) meningitis in genitourinary medicine clinic: a case report
}

This article was published in the following Dove Press journal:

International Medical Case Reports Journal

3 March 2014

Number of times this article has been viewed

\section{Ahmad K Abou-Foul \\ Thajunisha M Buhary \\ Sedki L Gayed}

Department of Genitourinary Medicine, Royal Blackburn Hospital, East Lancashire Hospitals NHS Trust, Blackburn, UK
Correspondence: Sedki L Gayed Department of Genitourinary Medicine, East Lancashire Hospitals NHS Trust, St Peter's Health Centre, Church Street, Burnley, Lancashire, UK, BB I I 2DL Tel +44 I2 8264430 I

Email sedki.gayed@elht.nhs.uk
Introduction: Cases of idiopathic recurrent benign aseptic meningitis were first described by Mollaret. Today, herpes simplex virus (HSV) is considered the cause of most cases of Mollaret's meningitis.

Case report: A 40-year-old male was referred to our genitourinary medicine clinic with recurrent genital herpetic lesions. He had HSV-2-positive genital ulcers 8 years earlier. One year after the first infection, he developed severe recurrent attacks of headache associated with meningitis symptoms. The results of all radiological and biochemical tests were normal, but the patient reported a correlation between his attacks and genital herpes flare-ups. We diagnosed the patient with Mollaret's meningitis and started him on continuous suppressive acyclovir therapy, which resulted in marked clinical improvement.

Discussion: Mollaret's meningitis is a rare form of idiopathic recurrent aseptic meningitis that has a sudden onset, short duration, and spontaneous remission with unpredictable recurrence. We believe that the presence of concurrent or recurrent mucocutaneous herpetic lesions can aid its diagnosis, prior to which, affected patients usually have many unnecessary investigations and treatments. Therefore, detailed sexual history should be sought in all patients with aseptic meningitis, and clinicians should also ask about history of recurrent headaches in all patients with recurrent herpetic anogenital lesions. Continuous suppressive acyclovir therapy may reduce the frequency and severity of attacks and can dramatically improve lifestyle.

Keywords: HSV-2 virus, acyclovir, Mollaret's meningitis, recurrent aseptic meningitis, HSV-2 virus, viral meningitis, acyclovir

\section{Introduction}

Mollaret was the first to describe a rare form of meningitis that presented as recurrent and brief self-limiting attacks of fever, headache, vomiting, and meningeal irritation with no obvious etiology. ${ }^{1}$ Subsequently, all cases of idiopathic recurrent aseptic meningitis (RAM) were collectively called Mollaret's meningitis. ${ }^{2}$ Today, herpes simplex virus (HSV) type 2 (HSV-2) is thought to be the commonest cause of Mollaret's meningitis, underlying up to $84 \%$ of cases ${ }^{3}$ although other infectious and noninfectious causes have also been described. ${ }^{2}$ However, its diagnosis remains challenging despite the use of new sophisticated diagnostic tools, and some authors have advised restricting the term Mollaret's meningitis to cases with no confirmed etiology. ${ }^{2}$ The frequency and severity of attacks are variable, and severe forms can be incapacitating if appropriate antiviral therapies are not promptly used. Here, we describe a rare case of a patient with RAM who presented with recurrent and severe self-limiting bouts of headache and responded well to suppressive antiviral therapy. 


\section{Case presentation}

A 40-year-old man was referred to our genitourinary medicine clinic with chronic recurrent herpetic genital ulcers. His first attack occurred 8 years earlier following unprotected vaginal sexual intercourse. Swabs taken from these initial lesions tested positive for HSV-2 and negative for HSV type 1 (HSV-1). Treponema enzyme immunoassay (EIA) and Neisseria gonorrhea culture were also negative. The patient had a past medical history of migraines that started in adulthood as unilateral headaches and were controlled by triptans and simple analgesics.

One year after his first genital infection, the patient started to develop severe holocranial headaches with distinct characteristics, which failed to respond to usual migraine therapy. The headaches were associated with neck stiffness, mild photophobia, and bilateral pedal paresthesia, but there was no fever, vomiting, or other cranial or radicular neuropathy symptoms. The patient went to the emergency department many times, but his biochemical markers and a computed tomography brain scan were normal. The patient repeatedly refused diagnostic lumbar puncture, but serologic assays (HSV-1, CMV [cytomegalovirus], VZV [varicella-zoster virus], and human immunodeficiency virus) were negative apart from a positive HSV-2 immunoglobulin G titer.

He was clinically diagnosed with meningitis and commenced on empirical parenteral ceftriaxone and acyclovir, to which he responded very well. His attacks often recurred two to three times per month and were usually self-limiting in 3-5 days, regardless of their severity, with no residual functional impairment. The attacks were often triggered by emotional stress or heat and were sometimes preceded by genital herpetic eruptions, for which he was referred to our clinic. The distinctive correlation between his meningitic recurrent headaches and recurrent genital lesions as well as his normal previous diagnostic tests raised our suspicion of a possible Mollaret's meningitis diagnosis. We placed the patient on a continuous suppressive oral acyclovir therapy regimen (400 $\mathrm{mg}$ twice daily), which reduced the frequency of his headaches to one to two attacks every 2-3 months, each lasting 1-3 days. He has been on this regimen for 9 years. Attempts to reduce the total daily dose to $400 \mathrm{mg}$ or $600 \mathrm{mg}$ have led to a remarkable increase in the severity and frequency of his acute relapses, so the total daily dose of $800 \mathrm{mg}$ is being sustained indefinitely with regular follow-up in our clinic.

\section{Discussion}

In 1982, HSV was linked to Mollaret's meningitis when HSV-1 was detected in the cerebrospinal fluid of an affected patient. ${ }^{4}$ Today, HSV-2 (and less often HSV-1) is believed to be a leading cause of RAM. Its pathogenesis is not fully understood and may be due to retrograde seeding reactivation of the latent virus nested in the sensory ganglia. ${ }^{5}$ Aseptic meningitis is known to complicate primary genital herpes infection in $36 \%$ of women and $11 \%$ of men, but meningitis following subclinical infections has also been reported. ${ }^{6,7}$ Confirmed HSV-2 acute meningitis can recur in $19 \%-27 \%$ of cases, especially in HSV-1 seronegative patients similar to our case. ${ }^{3,8} \mathrm{HSV}-1$ seroprevalence is declining in many countries, including the UK, and the incidence of recurrent HSV-2-associated meningitis may be increasing. ${ }^{3,9}$

Practical diagnostic criteria for Mollaret's meningitis historically included absence of any detectable etiological agents. ${ }^{10}$ However, occurrence of concurrent or separate episodes of recurring mucocutaneous herpetic lesions, or detection of HSV DNA in the cerebrospinal fluid which can be positive in up to $82 \%$ of samples taken $2-5$ days after the onset of symptoms ${ }^{3}$ - can aid diagnosis. Characteristics of RAM are summarized in Table 1. In 30\% of cases, recurrent attacks can be preceded by nonspecific self-limiting constitutional symptoms as paresthesias, neuropathic pain, and arthralgias. ${ }^{3,6}$ Mollaret's meningitis usually resolves after a period of 3-5 years, but cases with longer periods, similar to our patient, have also been reported. ${ }^{2,11}$

The use of long-term suppressive rather than episodic anti-HSV therapy has shown satisfactory results in controlling HSV-2-associated Mollaret's meningitis, but this practice is not yet supported by high quality evidence. ${ }^{2,7}$ In our patient and other reported cases, daily acyclovir or valacyclovir has been generally well tolerated with good bioavailability, and has reduced the severity and frequency of attacks. ${ }^{7,11}$ Other medications such as colchicine and indomethacin have also been tried, but firm evidence of their efficacy is still lacking. ${ }^{12,13}$

Table I Characteristics of recurrent aseptic (Mollaret's) meningitis

I. Recurrent episodes of meningitis (headache, meningismus)

2. Spontaneous remission of symptoms

3. Episodes separated by symptom-free periods

4. Fever (not always present)

5. Transient neurological symptoms (in $50 \%$ of cases)

6. No permanent neurological sequelae

7. Probable causative agent is HSV-2 (anogenital symptoms absent in at least half of cases)

Note: Data from Farazmand et $\mathrm{al}^{6}$ and Mirakhur and McKenna. ${ }^{\prime \prime}$ Abbreviation: HSV-2, herpes simplex virus type 2. 


\section{Summary}

Incidence of HSV-2-associated recurrent meningitis is suspected to be increasing. However, most patients have unnecessary investigations and treatments prior to diagnosis, and some patients remain undiagnosed. History of herpetic anogenital infections should be sought in all patients with recurrent meningitic headaches and vice versa. Continuous antiviral therapy appears to reduce the frequency of attacks and can dramatically improve lifestyle.

\section{Author contributions}

AKAF contributed to the literature review and writing of the article. TMB contributed to the data collection and correction of the manuscript. SLG contributed to the conception of project and review/correction of article before submission.

\section{Disclosure}

The authors report no conflict of interests in this work.

\section{References}

1. Mollaret P. Méningite endothélio-leucocytaire multirécurrente bénigne. Syndrome nouveau ou maladie nouvelle? (Documents cliniques) [Recurrent benign endothelio-leukocytic meningitis. A new syndrome or a new disease? (Case reports)]. Rev neurol. 1944;76:657-658. French.
2. Pearce JM. Mollaret's meningitis. Eur Neurol. 2008;60:316-317.

3. Kallio-Laine K, Seppänen M, Kautiainen H, et al. Recurrent lymphocytic meningitis positive for herpes simplex virus type 2. Emerg Infect Dis. 2009;15(7):1119-1122.

4. Steel JG, Dix RD, Baringer JR. Isolation of herpes simplex virus type 1 in recurrent (Mollaret) meningitis. Ann Neurol. 1982;11(1):17-21.

5. Pişkin IE, Yarimay G. Mollaret meningitis: a case report. Turk J Pediatr. 2010;52(3):306-308.

6. Farazmand P, Woolley PD, Kinghorn GR. Mollaret's meningitis and herpes simplex virus type 2 infections. Int J STD AIDS. 2011;22(6): 306-307.

7. Ellerin TB, Walsh SR, Hooper DC. Recurrent meningitis of unknown aetiology. Lancet. 2004;363(9423):1772.

8. Omland LH, Vestergaard BF, Wandall JH. Herpes simplex virus type 2 infections of the central nervous system: A retrospective study of 49 patients. Scand J Infect Dis. 2008;40(1):59-62.

9. Davies N, Tang J, Ward KN. Herpes simplex virus type 2 and recurrent meningitis. Lancet. 2004;364(9433):501-502.

10. Bruyn GW, Straathof LJ, Raymakers GM. Mollaret's meningitis. Differential diagnosis and diagnostic pitfalls. Neurology. 1962;12: $745-753$.

11. Mirakhur B, McKenna M. Recurrent herpes simplex type 2 virus (Mollaret) meningitis. J Am Board Fam Pract. 2004;17(4):303-305.

12. Mora JS, Gimeno A. Mollaret's meningitis: report of a case with recovery after colchicine. Ann Neurol. 1980;8:631-633.

13. Wynants H, Taelman H, Martin JJ, Van den Ende J. Recurring aseptic meningitis after travel to the tropics: a case of Mollaret's meningitis? Case report with review of the literature. Clin Neurol Neurosurg 2000;102(2):113-115.
International Medical Case Reports Journal

\section{Publish your work in this journal}

The International Medical Case Reports Journal is an international, peer-reviewed open-access journal publishing original case reports from all medical specialties. Previously unpublished medical posters are also accepted relating to any area of clinical or preclinical science. Submissions should not normally exceed 2,000 words or

\section{Dovepress}

4 published pages including figures, diagrams and references. The manuscript management system is completely online and includes a very quick and fair peer-review system, which is all easy to use. Visit http://www.dovepress.com/testimonials.php to read real quotes from published authors. 